\title{
Criação de jogos mediativos: correspondências entre designers e rendeiras da Raposa - MA
}

\section{Creating mediative games: social conversation to the lacemakers from Raposa - MA}

ABOUD, Camila; Mestranda em Design; Universidade Federal do Maranhão - UFMA

camilaboud@gmail.com

NORONHA, Raquel, Doutora em Ciências Sociais; Universidade Federal do Maranhão - UFMA

raquelnoronha79@gmail.com

\section{Resumo}

A conversa social é um instrumento importante para se transformar realidades e muitas vezes precisam ser mediadas para que ocorram com êxito. O design anthropology possibilita metodologicamente estes processos e o designer tem papel decisivo como mediador e tangibilizador de cenários, conforme nos direciona Manzini (2015). Este artigo tem como objetivo apresentar o processo de elaboração de jogos mediativos como método de conversação e criação de cenários e mostrar a sua aplicabilidade no dia-a-dia de uma comunidade rendeira de São Luís, Maranhão. Também mostra a importância do designer como mediador de processos e como a ludicidade proporciona uma visão diferenciada sobre o tema escolhido.

Palavras Chave: conversa social; jogos mediativos; criatividade; renda de bilros.

\begin{abstract}
Social conversation is an important tool for transforming realities and often needs to be mediated to occur successfully. Design anthropology through marketing makes these processes possible and the designer plays a decisive role as mediator and bringing the setting to life, as pointed out by Manzini (2015). This article aims to present the process of elaboration of mediative games as a method of conversation and scenario creation, and to show its applicability in the daily life of a lacemaker community in São Luís, Maranhão, Brazil. It also shows the importance of the designer as a process mediator and how role playing games can provide a differentiated view of the chosen theme.
\end{abstract}

Keywords: social conversation; mediative games; creativity; bobbin lace. 


\title{
1 Introdução
}

No livro "Design when everybody designs" Manzini (2015), para explicar o significado de codesign, afirma que em um mundo conectado tudo funciona de forma interdisciplinar, inclusive o ato de projetar, salvas exceções quando são requeridas habilidades específicas. A noção de codesign apresentada por Manzini (2015, p. 48) está relacionada a conversas entre os designers e atores sociais implicados em um processo específico, que vão avançando em sua conversa social.

Nesta forma de trabalhar, tanto para elaborar projetos quanto para discutir temas sociais e problemáticas concernentes aos seus cotidianos, os stakeholders correspondem-se entre si e colocam suas visões de mundo de forma compartilhada. As tradições culturais, históricas e de costumes são respeitadas. Na pesquisa, o objeto de estudo são as relações estabelecidas em torno da cadeia produtiva das rendas de bilros de Raposa, cidade situada a $24 \mathrm{~km}$ de São Luís, no Maranhão. O codesign é uma cultura de projeto que nos permite entender o fazer das rendeiras e construir oportunidades para a sua produção. Além disso, o intuito é que trabalhemos como mediadores de processos. Assim, Manzini nos diz:

\begin{abstract}
o papel do especialista em design é o de mediador (em meio a diferentes interesses) e facilitador (de outros participantes, ideias e iniciativas), mas também compete ao designer a criatividade e cultura e a habilidade de imaginar amplos cenários e/ou propostas de design inéditas, além da possibilidade de usá-los como gatilhos para conversas sociais e sustentálas com novas ideias (MANZINI, 2015, p. 49, tradução nossa).
\end{abstract}

Sendo assim, para que haja um processo de codesign por meio da correspondência em uma comunidade artesã, precisamos conhecer as atividades deste local e compreender quais pontos podemos trabalhar em conjunto. Além disso, o respeito e a empatia são extremamente importantes para que o clima de confiança nos permita caminhar e construir conhecimento juntos.

Para facilitar a correspondência entre os atores, uma ferramenta bastante útil a instigar conversas sociais é jogo de tabuleiro. A criação e aplicação deste tipo de jogo possibilita que a conversa social e os temas abordados sejam discutidos de forma lúdica. Segundo Brandt (2008, p.1), "desde a década de 90 , alguns autores sugeriram jogos ou teatros como guias de metáforas para a interação entre designers e usuários". Estes jogos são ferramentas que propiciam conversas sociais de forma lúdica e descontraída. Eles são elaborados de forma customizada, com a função de detalhar e enriquecer as conversas com informações específicas do grupo com o qual será pesquisado.

O estágio em docência com os alunos da graduação em design da Universidade Federal do Maranhão, na disciplina de Projeto Gráfico II, nos permitiu acompanhar a atividade de criação dos jogos de tabuleiro, com o tema das rendeiras de Raposa. Como havíamos feito a pesquisa de campo anteriormente, todas as informações foram compartilhadas com os alunos que elaboraram os jogos, possibilitando a correspondência entre alunos de graduação, mestrado e as detentoras do saberfazer local. Tim Ingold (2018) nos direciona a pensar sobre os processos de correspondência a partir da dedicação da atenção que comunicamos ao mundo. Corresponder vem da capacidade que o ser humano tem de se comunicar e relacionar-se com outros atores. Ingold (2018) faz um trocadilho com a palavra responsabilidade, que em inglês lê-se responsibility. Sendo assim, através da morfologia da palavra tem-se response (responder) + ability (habilidade), que pode ser interpretado como a habilidade de responder/corresponder ao mundo. Portanto, através desses jogos pretendemos mediar as conversas com as rendeiras de forma a compreender sua correspondência com a comunidade em que estão inseridas. 
O objetivo deste artigo é analisar a importância do designer como mediador de processos na comunidade de rendeiras de Raposa e também detalhar o processo criativo na elaboração dos jogos mediativos e os resultados deles. Por fim, as considerações finais.

\section{Designer como mediador de processos}

O processo de codesign em uma visão tradicional está relacionado à interação do design com seus stakeholders e a discussão para planejar e criar novas visões e estratégias para determinados produtos (MANZINI, 2015, p. 48). No entanto, Manzini (2015, p. 49) traz o codesign para uma esfera onde os participantes junto aos designers conversam a respeito de temas sociais, que fazem parte da vida diária desses atores. Eles interagem colaborando, sugerindo novidades e participando através de seus conhecimentos. Os designers desempenham papel de mediadores de processos, e devem ter a habilidade de imaginar e criar cenários, utilizando-os como facilitadores para as conversas sociais, de forma a sustentá-las com novas ideias. O designer como mediador de processos deve compreender a realidade em que o artesão vive, seus costumes, sua cultura, o local e o contexto social em que está situado. Também precisam se despir de seus conceitos de vida e adentrar no universo do outro. É necessário que sejam criativos o suficiente para usar o conhecimento a seu favor, criando cenários que possibilitem compartilhar novas realidades com os artesãos.

Nesta pesquisa, o papel dos designers é o de compreender a realidade em que a comunidade de artesãs da Raposa está inserida. Para suportar a análise da cadeia produtiva das rendeiras de Raposa, utilizaremos a teoria de Jerome McCarthy, que compõe o mix de marketing, mais conhecido como 4Ps.

Os 4Ps de McCarthy explicavam, de maneira concisa, as práticas genéricas da gestão do produto vigentes na época: desenvolver um Produto (Product), determinar o Preço (Price), realizar a Promoção (Promotion) e definir o Ponto (Place) de distribuição (KOTLER, 2012, P.33).

A Cadeia Produtiva das rendeiras de Bilros de Raposa é analisada com inspirações nos 4 Ps do mix de marketing. Sendo assim: observamos como os preços dos produtos são formados; como os locais de venda dos produtos são estabelecidos; como a comunidade comunica seus produtos e como as rendas são pensadas, criadas e elaboradas pelas rendeiras. O porquê destes parâmetros será explicado no item "criação de jogos mediativos", mais adiante neste artigo.

A prática da correspondência, conforme Ingold (2013) explica, trata-se da forma como respondemos ao outro e a reciprocidade desta ação. Nesta pesquisa, esta prática é de extrema importância para compreendermos melhor o contexto da comunidade de rendeiras da Raposa. Juntos construímos relacionamentos que permite a todos nós visualizar o contexto presente e sugerir inovações, de uma forma conjunta. Esta prática tem origem a partir do conceito de design anthropology que se trata de duas disciplinas onde uma disciplina se utiliza da outra para atingir sua finalidade: o design com a prática do projetar e proporcionar ferramentas úteis para a antropologia, que se utiliza dessas ferramentas para compreender melhor o meio que está no cerne da pesquisa (Halse; 2013).

O codesign, por meio da mediação de processos, proporciona conversas sociais que possibilitam a criação de novos cenários e inovações. Além disso, elas também podem ser estabelecidas a partir de conexões que não ocorrem no dia-a-dia (HALSE et al, 2010, p. 15). 0 designer é um dos atores responsáveis por criar temas e ambientes que propicia este tipo de 
conversa. A pesquisa de campo que fizemos, possibilitou repassar os dados sobre a comunidade de rendeiras aos alunos de graduação. Foram usados slides explicativos com as informações colhidas. Além disso, houve o acompanhamento nas aulas para que os alunos pudessem obter mais informações. A própria construção do jogo já foi um processo compartilhado entre alunos de graduação, mestrado e orientadora. O objetivo era criar jogos de tabuleiros, com a finalidade de fomentar discussões entre as rendeiras. Estes jogos fizeram parte da construção dos cenários para que a conversa pudesse fluir melhor, obtendo mais informações das rendeiras, de forma lúdica, simples e divertida, gerando oportunidades de problematização e criação de cenários e possibilidades.

O item a seguir detalha melhor os dispositivos de conversação, necessários nas comunidades para discussão de assuntos que o codesign trabalha a partir da mediação de processos, mas que na vida diária das comunidades, normalmente, não são discutidos.

\section{Dispositivos de conversação}

Neste artigo, os dispositivos de conversação são jogos de tabuleiros, elaborados especificamente para criar um cenário no qual as rendeiras de Raposa pudessem falar sobre seu ponto de vista na comunidade. Um dos focos nesta ferramenta está em ativar a capacidade de imaginação dos atores. Segundo Noronha $(2016$, p.9) a possibilidade de imaginar novas alternativas por meio dos jogos mediativos possibilita gerar novas hipóteses para as situações cotidianas, permite ir além das hipóteses aceitas, pois como jogadores, os atores têm a oportunidade de inverter seus papéis e experimentam atuar colocando-se no lugar do outro.

Para Brandt (2008, p.04, tradução nossa) "os usuários são vistos como pessoas com experiências/competências práticas em suas tarefas diárias e os designers são encorajados a criar ambientes que permitam explorar e ativar estas atividades por meio do design". As rendeiras são as detentoras do conhecimento de sua atividade da confecção de rendas. Além da produção, muitas delas também têm seu ponto de venda para cuidar e administrar. Elas, mais do que qualquer outro estudioso no assunto, detém as habilidades práticas em seu dia-a-dia. O objetivo de um jogo neste artigo é simular situações da vida diária destas rendeiras de forma que elas consigam vislumbrar novas idéias em seu processo de produção e comercialização. Conforme Brandt (2008), o intuito destes jogos elaborados por designers é fazer com que os stakeholders extrapolem suas situações diárias e vivenciem outras novas, imaginando e criando alternativas e possibilidades, que em situações rotineiras não são cogitadas.

\section{O contexto da comunidade da Raposa para os jogos mediativos}

A proposta dos jogos surgiu como levantamento de dados para a dissertação do mestrado em design de uma das autoras. O objeto de estudo desta dissertação são as relações sociais e materiais estabelecidas entre os atores da cadeia produtiva de rendas de bilros de Raposa e para que a pesquisa fosse aprofundada, eram necessárias entrevistas ou alguma forma para compreender melhor o contexto em que as rendeiras vivem hoje suas relações na comunidade, como funciona seu negócio e como se planejam em termos comerciais.

A professora de Projeto Gráfico II do curso de design da Universidade Federal do Maranhão, Raquel Noronha, uma das autoras deste artigo, abriu espaço em sua aula para que a pudéssemos compartilhar com os alunos quais eram as percepções e informações que tínhamos a partir das visitas à Raposa e assim, trabalharmos juntos a elaboração dos jogos mediativos. 
Começamos levando dados históricos e sociais a respeito da própria comunidade de rendeiras: Raposa é uma cidade formada por cearenses vindos de Acaraú. A migração aconteceu por volta dos anos 1950 a 1960 devido à seca que atravessou o Ceará (TAVARES, 2015, p. 15). Os moradores de Acaraú tinham peixes diversos no mar, mas não conseguiam fazer a farinha e todos os complementos para sua alimentação, devido ao solo seco e ruim para plantação. Por este fato, alguns deles, sabendo que as terras maranhenses eram bastante férteis, viajaram com o intuito de se instalar naquele local e aproveitar esse solo para sua agricultura local. Os migrantes cearenses eram pescadores em sua maioria e junto com eles foram suas esposas (rendeiras de bilros) e seus filhos (TAVARES, 2015, p. 15). Com o passar dos anos, a atividade pesqueira foi transmitida aos filhos homens, assim com as atividades das rendas de bilros foram transmitidas para as filhas pelas mães, avós e assim por diante. Hoje há uma avenida principal na cidade de Raposa, onde estão instaladas diversas lojas, onde as rendeiras vendem seus produtos. A maior parte destas rendas são feitas em Raposa, mas algumas vezes elas são levadas de Acaraú.

Para o desenvolvimento do jogo, foi necessário delimitar um assunto central, como um objetivo maior que relaciona todas as jogadas. Como a graduação de uma das autoras foi em administração, o assunto central escolhido, a partir também das observações feitas em campo, foi o Mix de Marketing definido por Kotler e Keller (2006, p. 17) "como o conjunto de ferramentas de marketing que a empresa usa para perseguir seus objetivos de marketing". Ao observar as práticas comerciais deste local, percebemos que a comercialização é realizada a partir das experiências que possuem com a venda das rendas. Com a finalidade de ampliar a visão dessas rendeiras do ponto de vista comercial, o mix de marketing foi escolhido como inspiração para a criação dos jogos.

Para Kotler e Keller (2006, p. 17), "O marketing envolve a identificação e a satisfação das necessidades humanas e sociais. Para defini-lo de uma maneira bem simples, podemos dizer que ele "supre necessidades lucrativamente"." A questão do relacionamento entre rendeiras (comerciantes) e compradores na Raposa, pode ser estrategicamente pensada como um local onde a propaganda boca-a-boca dos turistas é transmitida a outras pessoas de forma positiva, onde eles próprios (turistas) voltam para fazer novas compras ou indicam este local para compras de novos turistas.

O conceito de marketing foi usado de forma bastante simples, a partir da percepção de como ele aparece no cotidiano das rendeiras. Isto ocorreu para que elas pudessem compreender o que era dito e serem instigadas a usar novas estratégias comerciais em seu dia-a-dia. Estes jogos mediativos de design tiveram o objetivo de levantar conversas que dessem a oportunidade delas pensarem novas formas de agir em seu comércio e na elaboração das rendas de bilros, trazendo mais clientes, diferenciando seus produtos, tendo a oportunidade de aumentar seu mercado consumidor, valorizar este fazer e aumentar seus lucros.

O marketing é uma disciplina bastante ampla, por isso focamos o Mix de marketing. Segundo Kotler e Keller (2006, p. 17) esta ferramenta é dividida em quatro amplos grupos, denominados os 4Ps do marketing: são eles produto, preço, praça (ou ponto-de-venda) e promoção. Descreveremos cada um destes Ps separadamente e quais foram as observações da pesquisa de campo consideradas para a elaboração dos jogos.

O preço é o único elemento do mix de marketing que produz receita; os demais produzem custos. Ele também é um dos elementos mais flexíveis: pode ser alterado com rapidez, ao contrário das características de produtos, dos compromissos com canais de distribuição e até das promoções. O preço também informa ao mercado o posicionamento de valor 
pretendido pela empresa para seu produto ou marca. Um produto bem desenhado e comercializado pode determinar um preço superior e obter alto lucro (KOTLER; KELLER; 2006, p. 428).

O preço deve refletir e valorizar o trabalho das rendeiras, mas precisa também ser adequado a todo ambiente, local e atendimento, além das embalagens oferecidas. Hoje, o corredor de rendeiras se trata de um lugar com vários concorrentes. Além disso, o preço deve ser acessível ao consumidor que frequenta a Raposa, senão o estoque fica cada vez maior e as rendeiras perdem de ganhar com o volume de vendas. Na Raposa, o preço das rendas algumas vezes muda nas negociações das rendeiras com os clientes. Não há um preço tabelado a ser seguido. Outro aspecto a ser considerado com relação a formação do preço está no valor que se paga pela hora de trabalho da rendeira. Se a rendeira fosse paga por hora, receberia em torno de 40,00 reais por dia trabalhado (seguindo como parâmetro o salário mínimo brasileiro, hoje no valor de 954,00 reais). Cada peça leva em torno de 15 a 30 dias para ficar pronta. Seria, a partir do ponto de vista delas impossível vender uma blusa pelo valor de 500,00 reais ou mais. Isso desvaloriza e desestimula o próprio trabalho das rendeiras. Hoje, as blusas são vendidas em média por 90,00 reais e as saias por 200,00.

Para Kotler (1993, p. 506) "um produto é algo que pode ser oferecido a um mercado, para sua apreciação, aquisição, uso ou consumo, que pode satisfazer um desejo ou uma necessidade". 0 corredor de rendeiras possui várias lojas que oferecem blusas, saias, vestidos, caminhos de mesa, porta-copos, entre outros produtos feitos de renda de bilros. Estas rendas muitas vezes têm o mesmo desenho em todo o corredor de rendeiras, pelo fato de que nem todas conseguem desenvolver novos "papelões", que são espécies de moldes, para a confecção de novas peças. Outro aspecto a ser pensado são os tamanhos dos vestuários $(P, M, G)$ que não seguem um padrão na produção. Por isso, tanto os novos desenhos da renda, quanto os novos modelos, ficam prejudicados pela falta de conhecimento na elaboração deste componente. Hoje apenas duas rendeiras detém o conhecimento dos "papelões" na Raposa. No entanto, elas não o transmitem para as demais rendeiras e também não repassam novos papelões para que as outras possam diferenciar seus produtos.

Poucos produtores vendem seus bens diretamente aos usuários finais. Pelo contrário, a maioria recorre a intermediários para levar seus produtos ao mercado. Desta forma, todos eles têm a intenção de criar um canal de distribuição: um conjunto de organizações interdependentes que fazem com que o produto ou serviço esteja disponível para seu uso ou consumo por parte do consumidor particular, ou por outras empresas (KOTLER; ARMSTRONG, 1998, P. 420, tradução nossa).

A praça se refere ao local de venda dos produtos. A Raposa possui uma rua principal, à qual os moradores chamam de corredor das rendas. Neste local, as rendeiras e comerciantes possuem lojas que o produto principal são as rendas de bilros. Além destes pontos de vendas, as rendeiras também disputam os pontos nas feiras de São Luís, MA. No entanto, existem outros locais que ainda não foram explorados e que podem servir como novos pontos de vendas: Feiras fora de São Luís, lojas voltadas para a moda, lojas em shoppings, lojas de artesanato e até mesmo atravessadores.

Mix de comunicação de Marketing se trata de um conjunto de ferramentas de publicidade, promoção de vendas e relações públicas, vendas diretas e marketing direto que a empresa utiliza para comunicar de forma persuasiva o valor para o cliente de suas relações com ele (KOTLER; ARMSTRONG, 1998, P. 420, tradução nossa).

O último dos Ps é Promoção, que também podemos chamar de mix de comunicação de marketing. Este item do mix de marketing tem significativa importância para o fomento da 
valorização do trabalho e da cultura das rendas de bilros. Hoje ainda, muitos dos clientes e turistas não sabem que a Raposa, no Maranhão, é um local de produção de rendas e também desconhecem o tempo que se demanda para confeccionar uma peça. A promoção (ou comunicação) deste lugar e das rendeiras é essencial para fomentar o mercado local e para torná-las conhecidas, permitindo que a partir desta ação as rendeiras da Raposa possam ser vistas e valorizadas culturalmente por meio deste fazer.

A partir destes dados, os jogos começam a ser pensados e criados.

\section{Criação dos jogos mediativos}

Por meio da materialidade do jogo, a pesquisa de campo ganhou forma e se transformou em um artefato criado com a finalidade de se constituir em uma ferramenta de elicitação:

Criar é, basicamente, formar. É poder dar uma forma a algo novo. Em qualquer que seja o campo da atividade, trata-se, nesse "novo", de coerências que se estabelecem para a mente humana, fenômenos relacionados de modo novo e compreendidos em termos novos. $\mathrm{O}$ ato criador abrange, portanto, a capacidade de compreender; e esta, por sua vez, a de relacionar, ordenar, configurar, significar (OSTROWER apud PAROLIN, 1986, p. 09).

O processo de criação dos jogos mediativos permitiram que observações e visões diferentes pudessem ser expostas como temas de rodadas de jogo. Todos os jogos foram elaborados pensando as relações que a materialidade deles permitiriam a todos os jogadores visualizar. Assim, a compreensão dos problemas da Raposa ocorreu inicialmente de forma superficial para que os jogos pudessem ser elaborados. Depois estes pontos foram classificados e organizados de forma a se entender quais eram os principais ou secundários. E após tudo isso, ganharam significados dentro do jogo.

Segundo Ostrower (1986) “A imaginação criativa levantaria hipóteses sobre certas configurações viáveis a determinada materialidade. Assim, o imaginar seria um pensar específico sobre um fazer concreto". A partir desta ideia de criação, a técnica escolhida para elaborar os jogos teve origem nos mapas mentais.

Os mapas mentais são um método de armazenar, organizar e priorizar informações (em geral no papel), usando Palavras-chave e Imagens-chave, que desencadeiam lembranças específicas e estimulam novas reflexões e ideias. Cada ativador da memória em um Mapa Mental é uma chave que dá acesso a fatos, idéias e informações, além de liberar o verdadeiro potencial da mente, de modo que possamos nos tornar o que quisermos ser (BUZAN, 2009, p. 10).

A partir dos mapas mentais as ideias ganham forma e inicia-se o processo de elaboração da estrutura dos jogos. A importância destes jogos é fazer com que informações que poderiam ser obtidas de formas complexas, sejam colhidas por meio do lúdico, de jogos com ideias criativas e inovadoras. Criar e pensar possibilidades futuras é a atividade central destas tarefas, por meio de conversas que não são comuns ao dia-a-dia dessas rendeiras.

No início do projeto do jogo, mapas mentais foram elaborados para agrupar todas as atividades que giravam em torno das rendas de bilros. Para que os temas dos jogos não fossem repetidos, cada grupo ficou responsável pelos seguintes temas: Produto; Praça; Preço e União das Rendeiras. Foram mapeados também os stakeholders envolvidos nesta criação.

Seguem as Figuras 1 e 2 com exemplos dos mapas mentais elaborados. 
Figura 1 - Mapa Mental 1

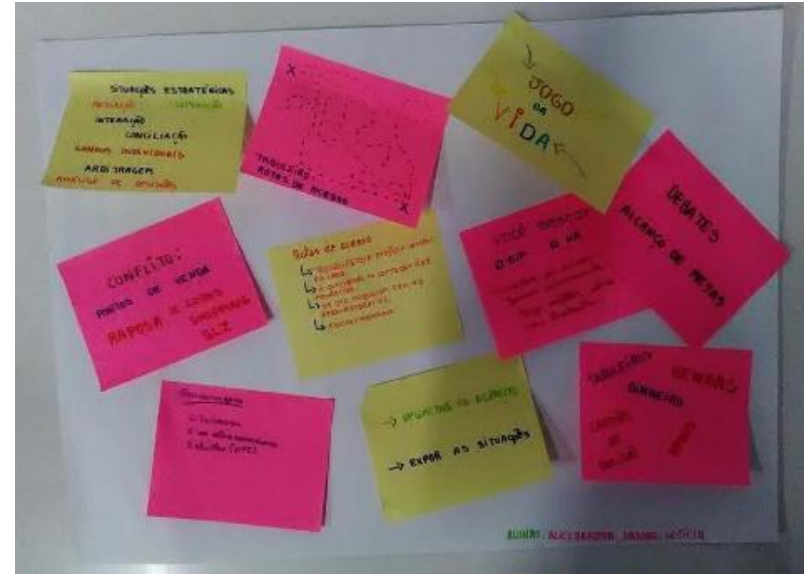

Fonte: autor (2017)

Figura 2 - Mapa Mental 2

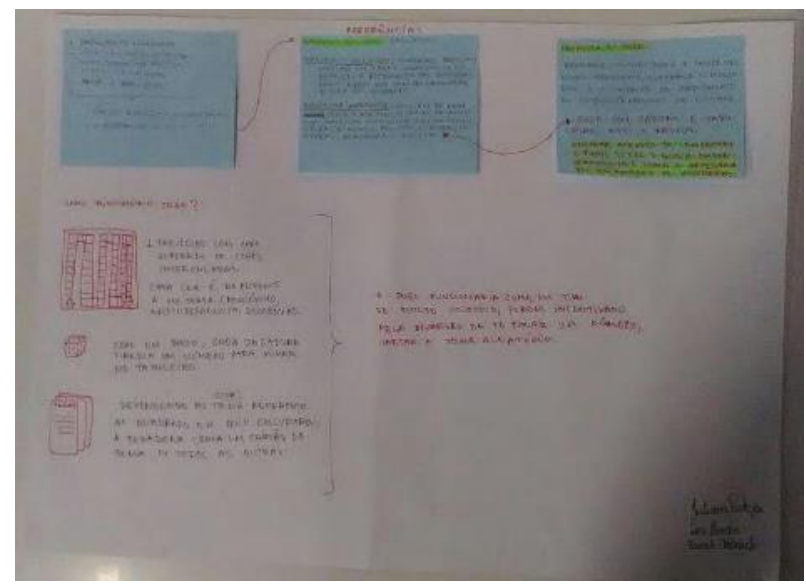

Fonte: autor (2017)

Depois da organização das ideias através dos mapas mentais, a materialidade dos jogos começou a ser planejada e elaborada. Nesta etapa, alguns alunos tiveram como parâmetros jogos de tabuleiros existentes, tais como Jogo da Vida e Banco Imobiliário. Sendo assim, eles criaram as próprias regras, o que permitiu focar a elaboração dos novos jogos no dia-a-dia das rendeiras.

Foram criados cinco jogos:

O primeiro inspirado no Jogo da Vida e no " $\mathrm{P}$ " de marketing relativo a "praça", descreve o caminho das rendeiras e dos atravessadores. As "casas" que compõem os caminhos possuem algumas armadilhas ou prêmios que dependem de opções dos jogadores ou questões a serem respondidas. Vence quem chega primeiro na última "casa".

O segundo jogo, inspirado no Banco Imobiliário e também no " $\mathrm{P}$ " de praça, ao invés de locais da cidade, mostra lojas e novos locais de vendas para que estas rendeiras repensem possibilidades de comercialização de seus produtos. Além disso, ao invés da casa "cadeia" foi criada a casa "UPA do Araçagy", que se trata da Unidade de Pronto Atendimento do Bairro do Araçagy, uma das unidades de saúde mais próximas de Raposa. 
O próximo jogo foi criado com inspiração na união das rendeiras, para mostrar que através das tramas as relações sociais são tecidas. Para isso, a equipe cortou fios de lã coloridas no tamanho de 1 metro. Cada participante deveria responder algumas perguntas elaboradas pelos alunos (descritas em cartas). E a cada resposta plausível a todos os participantes, o jogador poderia entrelaçar sua lã com a de seus colegas. O jogo termina quando as cartas de perguntas acabam e com isso, as tramas destas lãs lembram as rendas, representando as relações sociais destas rendeiras.

O quarto era semelhante a um pequeno tear em forma de círculo. Sua criação teve como tema a união das rendeiras também. No aro foram estabelecidos pontos pelos criadores do jogo e cada pergunta respondida em consenso com o grupo, permite às rendeiras ligar um pedaço contínuo de lã a estes pontos. Após completar todos os pontos e responder todas as questões, o pequeno tear apresentará a forma de estrela construída pelas respostas coletivas, representando a importância das relações das rendeiras.

O quinto e último jogo é um tabuleiro que representa o corredor das rendeiras e foi inspirado no "P" de produto. Este jogo mostra a importância das relações de trocas materiais para a manutenção da produção e a criatividade no fazer de cada uma delas, trocando linhas, e/ou tempo de produção e/ou até mesmo papelões, responsáveis pela criação de novos produtos. Além de materiais, a importância destas trocas permite às rendeiras compreender a relevância de seus relacionamentos e da boa convivência entre as rendeiras da comunidade de Raposa.

De acordo com Brandt (2008, p.04) "o que se enfatiza é que o design mostra perspectivas de futuros possíveis, ao invés de negociações atuais e manifestações dos olhares". Por meio dos jogos, podemos mostrar novas perspectivas e até mesmo assuntos que não são levados em conta na vida diária. Muitas vezes, por estarmos fora do ambiente das rendeiras, temos um certo distanciamento que nos permite ver situações com perspectivas diferentes e os jogos abrem possibilidades para que conversas sociais aconteçam com estas personagens principais, a fim de fazê-las se interessar por estes novos temas. Isso permite a elas se colocarem em papéis, posições e tarefas que anteriormente não executavam, a sair de sua zona de conforto. Estes jogos, são oportunidades para que as artesãs olhem para seu negócio e consigam vislumbrar novos cenários.

Figura 3 - Jogo de Tabuleiro 1

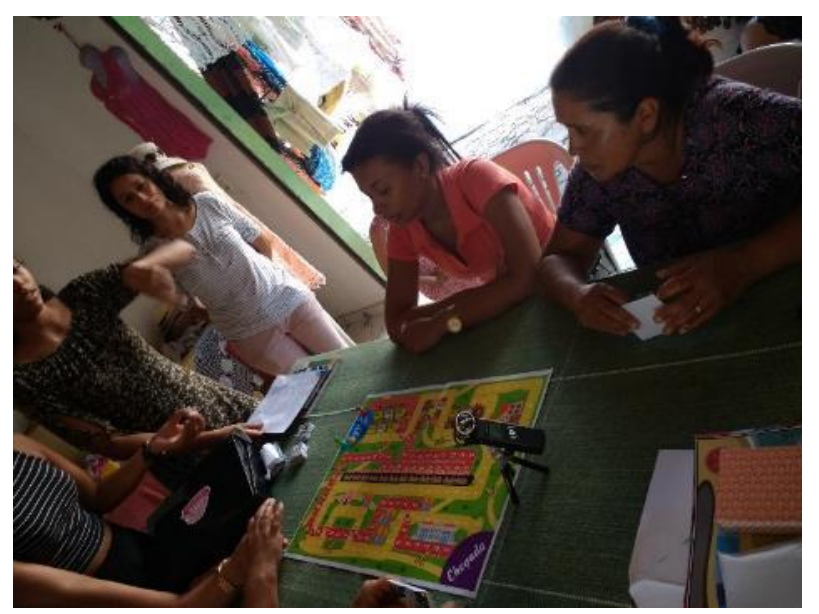

Fonte: autor (2017) 


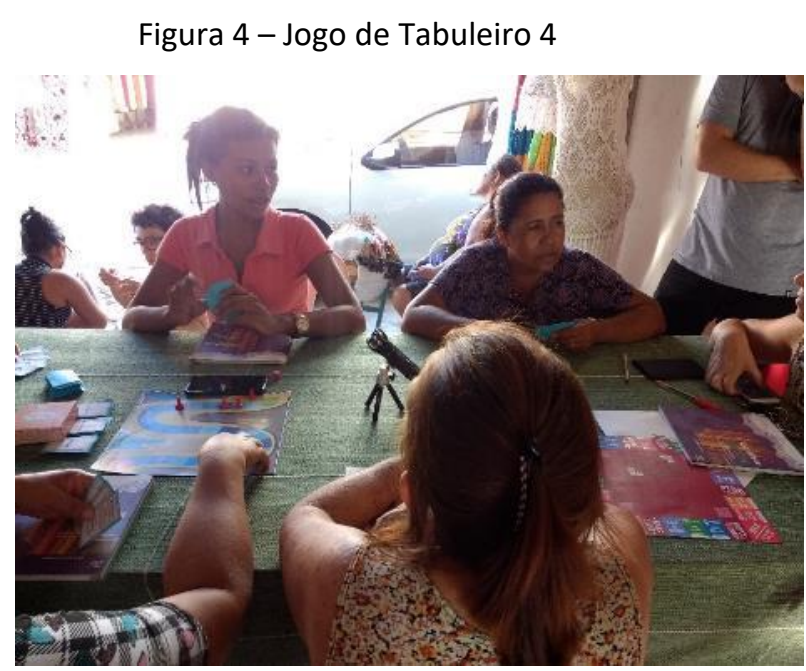

Fonte: autor (2017)

O time de design aprende mais expondo seus diferentes interesses e interpretações ao longo das mesmas linhas que todos os outros participantes. Eles são os responsáveis pelo design deste trabalho e não há argumentos do porquê que eles não deveriam também deixar seus interesses e interpretações se tornarem passíveis de serem explorados juntos. Ao dizer isto, não significa que os facilitadores são desnecessários nos jogos. Nos nossos jogos, os designers jogam em dobro, ambos como facilitadores e jogadores, tomando papéis ativos (BRANDT, 2008, tradução nossa).

Após a elaboração dos jogos, os mesmos precisam ser testados. Tanto os alunos, quanto outros participantes devem se posicionar como jogadores para se certificar da funcionalidade do mesmo. Na maior parte das vezes, os ajustes são propostos após algumas rodadas dos jogos e então eles estão prontos para serem jogados com as rendeiras de bilros de Raposa.

\section{Resultados}

Através do jogo, pudemos observar que as rendeiras acreditam que a união delas é importante para alcançar seus objetivos, no entanto, a prática acontece de forma oposta ao que dizem. Algumas rendeiras seguem a líder formal da associação. Outras seguem outra líder informal. Isso faz com que a força que elas poderiam ter ao estar unidas, se enfraqueça. A partir daqui, podemos perceber que como afirma:

O modo de sentir e de pensar fenômenos, o próprio modo de sentir-se e pensar-se, de vivenciar as aspirações, os possíveis êxitos e eventuais insucessos, tudo se molda segundo ideias e hábitos particulares ao contexto social em que se desenvolve o indivíduo. Os valores culturais vigentes constituem o clima mental para seu agir. Criam as referências, discriminam as propostas, pois conquanto os objetivos possam ser de caráter estritamente pessoal, neles se elaboram possibilidades culturais. Representando a individualidade subjetiva de cada um, a consciência representa a sua cultura (Ostrower apud Parolin, 2003, p. 16).

Devido às barreiras de convivência, muitas vezes, o grupo deixa de se beneficiar com ações que propiciariam mais união e interação entre as participantes. Hoje percebemos que estas barreiras precisam ser superadas para que o grupo esteja unido e agindo em conjunto, o que permitiria a elas ter mais força como cidadãs de buscar seus ideais em conjunto.

O jogo que teve como tema o " $\mathrm{P}$ " de produto, possibilitou conversas a respeito da 
importância da diferenciação do mesmo, seja nos desenhos, modelos ou tipos de produto. A partir desta discussão, foi debatida a importância de se elaborar novos "papelões", pois é a partir deles que há a possibilidade da criação de novos produtos. Por não ter alguém que as ensine, as rendeiras continuam produzindo as peças que estão no seu arquivo de papelões. Percebemos, por meio dos jogos, que elas têm vontade de aprender a elaborá-los. No entanto, devido a complexidade desta atividade, muitos acabam por usar os mesmos papelões já existentes.

Outro " $p$ " discutido por meio destes jogos foi praça ou ponto-de-venda. As próprias rendeiras acreditam que novos lugares para a venda das rendas podem ser benéficos a todas elas. No entanto, acabam ficando no mesmo ponto de venda sempre e brigando pelas mesmas feiras. Por meio dos jogos, a questão dos espaços virtuais, seja na internet ou nos aplicativos dos smartphones foram cogitados. Também pudemos apontar os atravessadores, muito desconsiderados por elas devido à baixa valorização que dão ao trabalho dessas rendeiras.

\section{Considerações Finais}

Jogar permitiu às rendeiras pensar cenários de situações com as quais elas não atuam em seu dia-a-dia. Estes cenários são importantes para se entender a realidade das situações presentes: a satisfação com seu trabalho, as perspectivas de futuro e os possíveis caminhos que podem começar a trilhar para que o cenário atual ganhe maior visibilidade, tendo como ponto de partida os 4Ps do mix de marketing: preço, praça, produto e promoção.

Uma das particularidades que influenciam na oferta de produtos na Raposa é o conhecimento na elaboração dos papelões. Isto impede que novos desenhos sejam criados, formatos de roupas sejam adequadas aos tamanhos padrões $\mathrm{P}, \mathrm{M}, \mathrm{G}$ especificados pelo mercado.

Outro aspecto descoberto é em relação aos pontos de vendas. Estas conversas sociais propiciaram que as rendeiras considerassem novos pontos de venda, tendo em vista que o corredor de rendeiras e as feiras de artesanato em São Luís são locais bastante disputados. O ambiente virtual foi cogitado nas conversas, assim como lojas de artesanatos, feiras internacionais entre outros.

A união das rendeiras, de forma que uma ajude a outra a prosperar, foi vista como uma das barreiras na Raposa. Muitas delas por focar o próprio negócio e considerar as vizinhas como concorrentes, deixam de ganhar com o trabalho coletivo e perdem benefícios por isso. A união permitiria uma divisão de custos com feiras maiores e que todas pudessem expor juntas seus produtos.

A partir desta pesquisa, é possível entender que o papel dos designers totalmente focados na elaboração de projetos com produtos físicos está mudando. O codesign propiciou o fomento de conversas sociais onde os designers atuam como mediadores de processos.

A aplicação dos jogos com as rendeiras nos possibilitou compreender melhor o dia-a-dia delas, sugerir novas alternativas para comercialização das rendas e trocar experiências sobre este fazer.

A experiência de participarmos na elaboração e aplicação de jogos mediativos com alunos da graduação em design da UFMA e as rendeiras de bilros da Raposa foi uma tarefa que proporcionou o compartilhar de experiências e pontos de vistas diferentes e nos permitiu trabalhar em um processo de codesign. O cuidado na elaboração das principais questões dos jogos era sempre levado em conta, pois a ideia central da construção destes jogos era permitir novos pontos de vistas para as rendeiras, para os alunos e para nós pesquisadoras. 


\section{Referências}

BRANDT, Eva et al. Formating Design Dialogues - Games and Participation. In: BINDER, T.; BRANDT, E.; GREGORY, J. (guest editors). CoDesign - International Journal of CoCreation in Design and the Arts, Volume 4, Number 1, p. 51-64. Taylor \& Francis. March 2008.

BUZAN, Tony. Mapas Mentais. Rio de Janeiro: Sextante, 2009.

HALSE, Joachin. Ethnographies of the Possible. In: GUNN, Wendy; OTTO, Ton; SMITH, Rachel Charlotte. Design Anthropology: Theory and Practice. London, UK: Bloomsbury, 2013, p. 180-196.

HALSE, Joachin. Rehearsing the future. Copenhagen: The Danish Design School Press, 2010. 211p.

INGOLD, T. Making: anthropology, archeology, art and architecture. London: Routledge, 2013. 163p.

KOTLER, P. Administração de Marketing - Análise, Planejamento, Implementação e Controle. 3 ed. São Paulo: Atlas, 1993.

KOTLER, Philip; ARMSTRONG, Gary. Principios de Marketing. 12a Edição. Madrid, Espanha: Prentice Hall, 2008. $880 \mathrm{p}$.

KOTLER, Philip; KELLER, Kevin Lane. Administração de Marketing. 12a Edição. Brasil: Prentice Hall, 2006. 776 p.

MANZINI, Ezio. Design, when everybody designs. An introduction to Design for Social Innovation. Cambridge/London: The MIT Press, 2015. 241 p.

NORONHA, Raquel. Imaginar, materializar e jogar: correspondências entre o design e a antropologia e a prática projetual em jogos mediativos. In: Anais 30a Reunião Brasileira de Antropologia. João Pessoa. 2016.

OSTROWER, Fayga. Criatividade e processos de criação. Petrópolis: Editora Vozes, 1987. 167 p.

PAROLIN, Sonia Regina H. A criatividade nas organizações: um estudo comparativo das abordagens sócio interacionistas de apoio à gestão empresarial. Caderno de Pesquisas em Administração. São Paulo, v.10, n.1, 2003.

ROCHA, Rudimar Antunes da; PLATT, Allan Augusto. Administração de Marketing. 3a Edição. Florianópolis: Departamento de Ciências da Administração/UFSC, 2015. 166 p. Disponível em: $<$ http://arquivos.eadadm.ufsc.br/EaDADM/UAB3_2013-

2/Modulo_5/ADM_MKT/material_didatico/adm-marketing-3ed-alterado.pdf>. Acesso em 25/ jan. 2018.

TAVARES, Flavia Cerveira. Raposa Redes e Rendas. Rio de Janeiro: IPHAN. 2015. 36 p. 